organ invasion. Australas Radiol. 2007;51:346-350

7. Bulakçı M, Kartal MG, Yılmaz S, Yılmaz E, Yılmaz R, Şahin D, et al. Multimodality imaging in diagnosis and management of alveolar echinococcosis: an update. Diagn Interv Radiol. 2016;22(3):247-56.

8. Bresson-Hadni S, Koch S, Beurton I, et al. Primary disease recurrence after liver transplantation for alveolar echinococcosis: long-term evaluation in 15 patients. Hepatology. 1999;30:857-864.

9. Koch S, Bresson-Hadni S, Miguet JP, et al. Experience of liver transplantation for incurable alveolar echinococcosis: a 45 case European collaborative report. Transplantation. 2003;75:856-863.

\section{Non Cirrhotic Portal Hyperten- sion with a Large Spontaneous Splenic Abscess}

In the western world, non-cirrhotic portal hypertension $(\mathrm{NCPH})$ is a rare disease. However in the Indian subcontinent, it is estimated that over $30 \%$ of cases of variceal bleeds are due to $\mathrm{NCPH}$ or extra hepatic portal venous obstruction (EHPVO). Multiple splenic abscesses are a rare condition in clinical practice, and are seen mostly in immune-compromised patients or in those presenting following an intervention. ${ }^{1}$ There are also reports of such spontaneous abscesses developing in the setting of enteric fever or infective endocarditis. Reports have suggested that ultrasound-guided percutaneous drainage is a safe and feasible alternative to surgery in the treatment of splenic abscesses allowing splenic preservation. ${ }^{2}$ A search through available literature has shown several reports of splenic abscesses developing after splenic artery embolisation. Splenectomy is reserved for those cases where medical treatment has failed. To the best of our knowledge, the development of a spontaneous splenic abscess in a cirrhotic patient has only been described in one prior case report by Cacopardo et al. ${ }^{3}$ There are no prior descriptions of such a case in a patient with NCPF.

\section{Case Report}

We report the case of a 39 year old clerk who was diagnosed with chronic hepatitis B in 2011 and has been on tenofovir for the same. He presented to our emergency with a history of progressively worsening abdominal distension for the last 3 months and intermittent high grade fever for 2 months. He did not report hematemesis, melena or altered sensorium. He denied any prior abdominal trauma or surgery, chest pain, shortness of breath, palpitations, cough or altered bowel habits. On physical examination he was found to be pale, icteric, severely sarcopenic and had a tender massive splenomegaly, palpable $15 \mathrm{~cm}$ below the left hypochondrium extending up to the pelvis. He was found to have evidence of anemia, hyperbilirubinemia and hypoalbuminemia upon investigation. His INR was 2.4 and thromboelastography showed global coagulation failure requiring correction. Serum alkaline phosphatase was grossly elevated to $213 \mathrm{IU} / 1$ with mild elevation of other liver enzymes. CT imaging of the abdomen revealed a normal appearing liver, massive splenomegaly and a patent dilated portal venous system with multiple collaterals and a large lienorenal shunt. The spleen showed a large abscess about $15 \times 21 \times 10 \mathrm{~cm}$ in size, with no evidence of rupture (Figure 1 and 2). Iron studies showed elevated serum ferritin, and transferrin saturation-71.2\%. Gastroduodenoscopy did not show any varices or portal hypertensive gastropathy. His transjugular liver biopsy showed evidence of chronic hepatitis, and hepatic venous portal gradient was just $4 \mathrm{~mm} \mathrm{Hg}$ confirming the clinical suspicion of non cirrhotic portal hypertension (Figure 3 and 4). Malaria antigen test, widaltitres and viral serologies for hepatitis A, C, E, herpes simplex, cytomegalovirus and Ebstein Barr virus were all negative. His HBsAg and anti HBe were reactive without detection of HBV DNA or HBeAg. Interestingly, on immuno-phenotyping of CD4 and CD8 lymphocytes, he was found to have CD4 lymphocytopenia with a CD4 count of 195 cells/ $\mu$ l. However his CD4/CD8 ratio was within normal limits and IgG was $13.1 \mathrm{~g} / \mathrm{l}$. HIV-1 and 2 and HIV 1 RNA were non-reactive and there was as no evidence of lymphoma or parasitic infections. 2D Echocardiography did not reveal any endocarditis. Bone marrow biopsy aspirate showed evidence of a reactive 


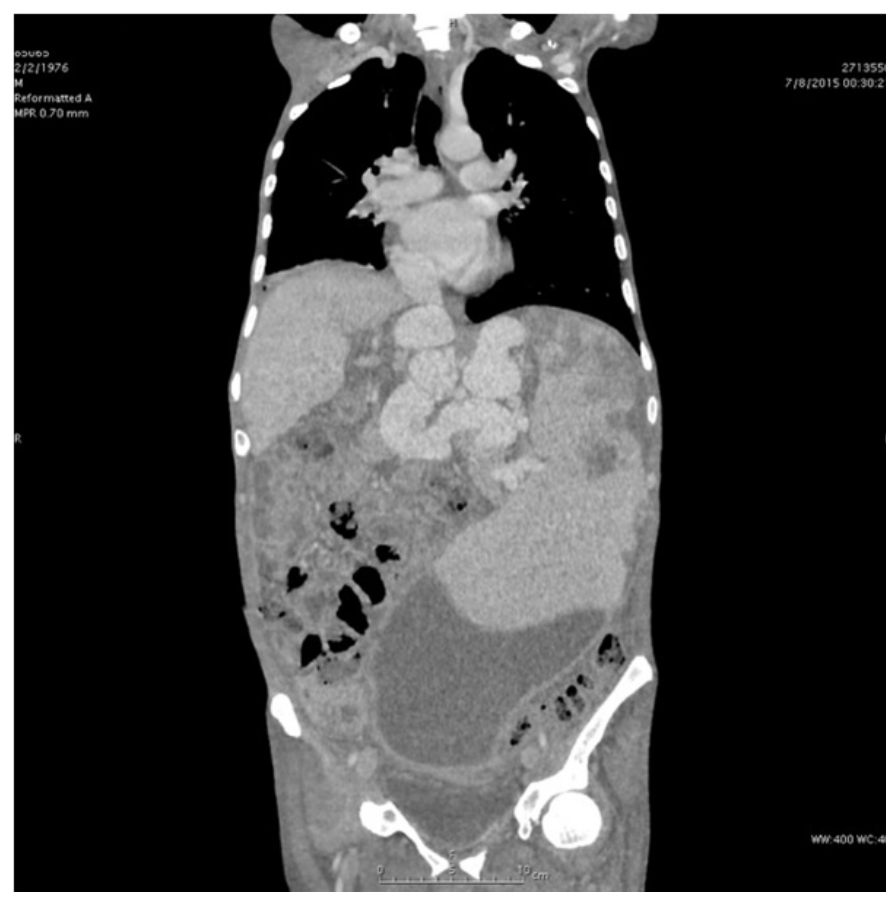

Figure 1: CT image showing large collaterals, massive splenomegaly and splenic abscess at the lower pole extending up to the pelvis.

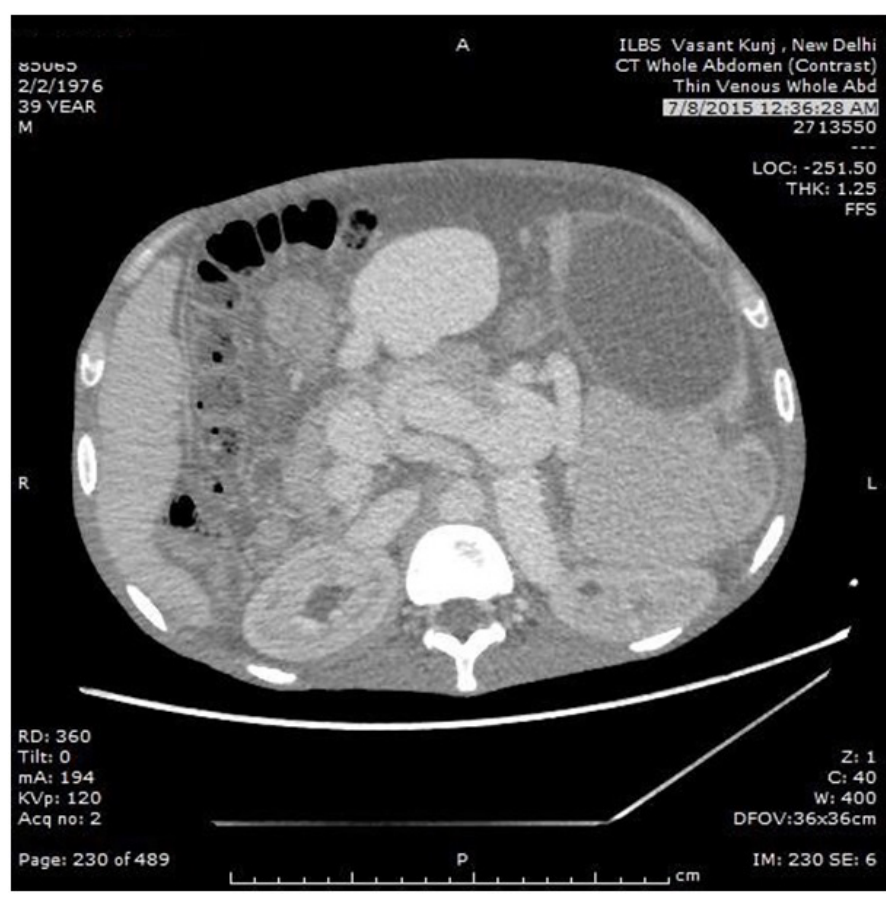

Figure 2: CT image showing a slightly shrunken liver with an $18 \mathrm{~mm}$ lieno-renal shunt.

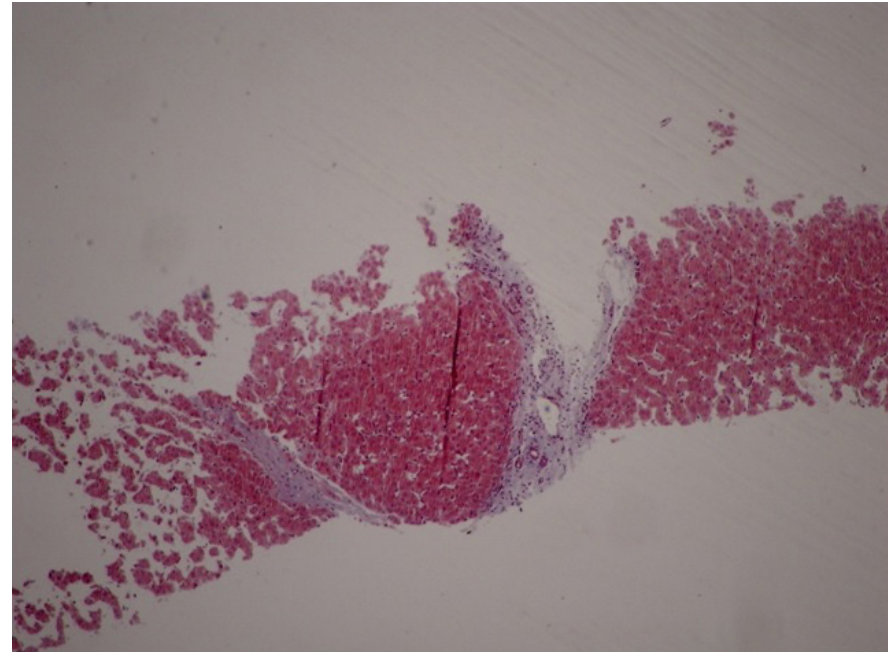

Figure 3: Transjugular liver biopsy specimen showing normal liver parenchyma with only grade 1 fibrosis consistent with NCPF; Masson Trichrome stain $10 \mathrm{x}$.

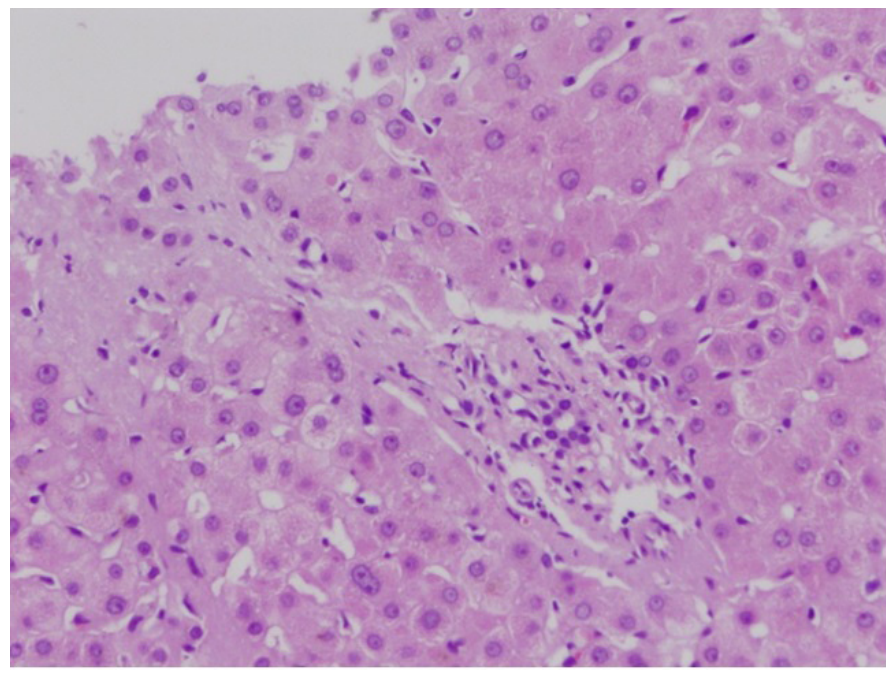

Figure 4: Liver biopsy specimen showing largely preserved parenchyma and a normal portal tract. Hematoxylin and eosin stain : $40 \mathrm{X}$.

marrow with no abnormal cells, with increased cellularity (75\%) and normal trilineagehematopoiesis.

He was transfused as per the results of thromboelastography to correct anemia and coagulopathy following which ultrasound guided percutaneous drainage (PCD) of the largeabscess was done, immediately draining $2 \mathrm{~L}$ of pus. Gram stain of the pus showed acute suppurative inflammation on cytology. Pus culture showed growth of multi-drug resistant (MDR) E. coli. Tuberculosis- 
polymerase chain reaction (TB-PCR), fungal stains and culture were negative. Amoebic and hydatid serologies were not reactive. On repeat scan a second collection in the left peri-splenic space was noted for which a second PCD was done which showed minimal fluid output. A third drainage tube was inserted on re-look sonography which showed a pelvic collection. Drains were left in situ for 4 weeks with eventual collapse of the abscess cavity with regression in splenic size to $5 \mathrm{~cm}$ below costal margin. All drains were removed by the fourth week. He received 4 weeks of intravenous followed by 8 weeks of oral antibiotics. The patient was afebrile after 5 days of antibiotics and drainage, and has remained well since then with improved nutritional status. He has a mild anemia $(\mathrm{Hb}-10.2 \mathrm{~g} / \mathrm{dl}$ ) and thrombocytopenia (platelet count $1.1 \times 107 / \mathrm{L}$ ) with normal INR. He is planned for interval splenectomy with creation of a proximal lieno-renal surgical shunt as definitive therapy.

\section{Discussion}

Splenic abscesses have been reported in the literature largely in the setting of post splenic artery embolisation for variceal bleeding or symptomatic hypersplenism. Patients present between 10 days to 3 months following splenic artery embolisation. ${ }^{1}$ Treatment of these splenic abscesses include percutaneous drainage and antibiotics, or occasionally, splenectomy. Mortality rates range from $0.1 \%-6.3 \%$ of patients undergoing splenic artery embolisation, and the formation of a splenic abscess is the predominant cause of death. Another setting for the development of a splenic abscess has been described after endoscopic sclerotherapy due to embolisation of the sclerosant causing retrograde thrombosis.

According to the consensus statement of the Asia Pacific Association for the Study of the Liver (APASL) on NCPF, the disease accounts for approximately $10-30 \%$ of all cases of variceal bleed in several parts of the world including India. ${ }^{4}$ Sarin et al. proposed a unifying common hypothesis for both NCPF and extra hepatic portal vein obstruction wherein a major thrombotic event in the main portal vein at a young age results in EHPVO, whereas repeated microthrombotic events in smaller and mediumsized ( $<300$ micron) branches lead to NCPF. Shouten et al proposed that intrahepatic venous obstruction (obliterative venopathy) and increased splenic blood flow (due to high levels of endothelial nitric oxide synthase and inducible nitric oxide synthase) was the underlying basis for NCPF. Patients with NCPF commonly present with splenomegaly (74\%-97\%), variceal bleed (65\%-72\%), anemia (90\%), and ascites (10\%-25\%). ${ }^{5}$ Our patient had massive splenomegaly alone. He had never bled, nor had he any ascites.

\section{Immunological dysfunction in NCPH}

Spleno-portal axis abnormalities might be the consequence of multiple inflammatory states including autoimmune and infective. CD4(+) T cell counts were significantly lower among cirrhotic patients than among HIV-seronegative historic control subjects without liver disease. Abnormal CD4(+) T cell counts were associated with splenomegaly $(\mathrm{P}=.03)$, thrombocytopenia $(\mathrm{P}=.002)$, and leukopenia $(\mathrm{P}<.001)$. However, the percentage of $\mathrm{CD} 4(+) \mathrm{T}$ cells was normal in $95 \%$ of patients who had a low absolute CD4(+) T cell count. Our patient also had a low CD4 count, but his $\mathrm{CD} 4 \%$ and $\mathrm{CD} 4 / \mathrm{CD} 8$ ratio were normal. In cirrhosis, the immune disturbance is characterized by severe B cell defects., increased numbers of exhausted CD21, low B cells, and $\mathrm{T}$ cell activation pointing to an inflammatory or infective state. The reduced frequency of regulatory $\mathrm{T}$ cells might also contribute to autoimmunity and inflammation. ${ }^{6}$

Our patient had suffered a large splenic abscess, and is likely to need a splenectomy even though he was managed successfully by percutaneous drainage. In the setting of an already immune-compromised state, splenectomy might predispose him to opportunistic infections. In addition, removal of the spleen alone will lead to symptomatic portal hypertension with development of varices. Hence a surgical splenorenal shunt will also have to be created to decompress the portal venous system. He is therefore planned for combined splenectomy and shunt surgery. 
MADHUMITA PREMKUMAR ANAND KULKARNI TANMAY VYAS SHIVANI DUDHA Y K JOSHI

Department of Hepatology, Institute of Liver and Biliary Sciences, D1, Vasant Kunj, New Delhi, India

Corresponding Author: Dr Madhumita Premkumar Email:drmadhumitap@gmail.com

\section{References}

1. Chang KC, Chuah SK, Changchien CS, et al. Clinical characteristics and prognostic factors of splenic abscess: a review of 67 cases in a single medical center of Taiwan. World J Gastroenterol. 2006;12(3):460-4.

2. Schwerk WB, Görg C, Görg K, Restrepo I.Ultrasoundguided percutaneous drainage of pyogenic splenic abscesses. J Clin Ultrasound. 1994;22(3):161-6.

3. Cacopardo B, Sapienza M, Li Volsi S., Gussio M, Benenati P, Notararrigo C, Maiuzzo S.Description of a rare case of splenic abscess due to spontaneous E. coli bacteremia in a cirrhotic patient.Eur Rev Med Pharmacol Sci. 2008;12(5):331-4.

4. Sarin SK, Kumar A, Chawla YK, et al. Noncirrhotic portal fibrosis/idiopathic portal hypertension: APASL recommendations for diagnosis and treatment. Hepatology International. 2007;1(3):398-413. doi:10.1007/s12072007-9010-9.

5. Schouten JNL, Garcia-Pagan JC, Valla DC, Janssen HLA. Idiopathic noncirrhotic portal hypertension. Hepatology. 2011; 54: 1071-1081

6. Jackson BD, Doyle JS, Hoy JF, et al. Non-cirrhotic portal hypertension in HIV mono-infected patients. Journal of Gastroenterology and Hepatology. 2012;27:1512-1519.

\section{Multinodular Primary Hepatic Lymphoma in a Patient with HCV Related Cirrhosis}

Primary hepatic lymphomas are a rare neoplasm of obscure etiology. Recent case reports in Hepatitis $\mathrm{C}$ virus (HCV) positive patients have postulated possible role of $\mathrm{HCV}$ in their pathogenesis. Most cases present with a solitary large hepatic mass in a non-cirrhotic liver. We herein report a case of diffuse large B cell lymphoma (DLBCL) with germinal center phenotype presenting as multiple $>30$ liver nodules in a cirrhotic liver.

\section{Case Report}

We report a case of 53-year-old female who is a known seropositive for $\mathrm{HCV}$ since 10 years on medical management. She presented with complaints of jaundice for 6 months. She developed distension of abdomen and pedal edema 3 months back. No history of ascitic taps in the past. There is no history of upper GI bleed, spontaneous bacterial peritonitis, hepatorenal syndrome or hepatic encephalopathy. There was no past history suggestive of diabetes mellitus, hypertension, chronic obstructive pulmonary disease or asthma. She was admitted and evaluated for liver transplant. Her International Normalized Ratio (INR) at admission was 3.04 which later increased to 3.61. She was managed with fresh frozen plasma transfusions. She had ascites and an ascitic tap was performed under USG guidance with around 5 litres of fluid drained. Her ascitic fluid TLC count was $150 / \mathrm{mm}^{3}$. She was managed with intravenous antibiotics. Her Hemogram revealed Haemoglobin $11.2 \mathrm{mg} / \mathrm{dl}$, PCV

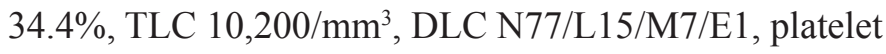
count $68,000 / \mathrm{mm}^{3}$. Liver function tests showed bilirubin total/direct 6.26/4.71mg/dl, AST 94IU/L, ALT 69IU/L, ALP 162IU/L, GGT 55IU/L, protein $5.8 \mathrm{~g} / \mathrm{dl}$, albumin 1.7g/dl, INR 3.04 and Fibrinogen $171 \mathrm{mg} / \mathrm{dl}$. Renal function test revealed BUN $16 \mathrm{mg} / \mathrm{dl}$, creatinine $1.0 \mathrm{mg} / \mathrm{dl}$. Hepatitis B surface antigen was found to be positive and Hepatitis B core antibody was reactive (9.850). Her anti$\mathrm{HCV}$ was positive and HCV RNA levels were 14500 $\mathrm{IU} / \mathrm{ml}$. HCV Genotype was 3. She tested negative for 